\title{
In Vitro Effects of Photodynamic Therapy with Three Photosensitizers on Candida spp from Complicated Vulvovaginitis and Asymptomatic Women
}

\author{
Humberto Fabio Boatto', Maria Sayonara de Moraes², Alexandre Paulo Machado', \\ Manoel João Batista Castelo Girão4, Gilglécia Novaes Pereira Santana5, \\ Fernanda Aparecida Vieira Fernandes ${ }^{5}$, Orion Sant'anna Motter Borba ${ }^{5}$, \\ Olga Fischman Gompertz ${ }^{5}$
}

\begin{abstract}
${ }^{1}$ Faculty of Medicine, University of Mogi das Cruzes, Mogi das Cruzes, São Paulo, Brazil
${ }^{2}$ Dermatologist of Sao Paulo State Secretary of Health, Sao Paulo, Brazil

${ }^{3}$ Department of Basic Health Sciences, Faculty of Medicine, Federal University of Mato Grosso, Cuiabá, Brazil

${ }^{4}$ Departament of Ginecology, Faculty of Medicine, Federal University of São Paulo, São Paulo, Brazil

${ }^{5}$ Departament of Microbiology, Imunology e Parasitology, Federal University of São Paulo, São Paulo, Brazil

Email: alepaulo@hotmail.com,olga.gompertz@unifesp.br
\end{abstract}

How to cite this paper: Boatto, H.F., de Moraes, M.S., Machado, A.P., Girão, M.J.B.C., Santana, G.N.P., Fernandes, F.A.V., Borba, O.S.M. and Gompertz, O.F. (2021) In Vitro Effects of Photodynamic Therapy with Three Photosensitizers on Candida spp from Complicated Vulvovaginitis and Asymptomatic Women. Open Journal of Medical Microbiology, 11, 283-297.

https://doi.org/10.4236/ojmm.2021.114018

Received: August 22, 2021

Accepted: October 30, 2021

Published: November 2, 2021

Copyright $\odot 2021$ by author(s) and Scientific Research Publishing Inc. This work is licensed under the Creative Commons Attribution International License (CC BY 4.0).

http://creativecommons.org/licenses/by/4.0/ (c) (i) Open Access

\begin{abstract}
Aim: To evaluate photodynamic therapy (PDT) in vitro to reduce the growth of Candida spp, and its synergy with the antifungals fluconazole and ketoconazole for inhibition of resistant, DDS and susceptible isolates from asymptomatic carriers and with complicated vulvovaginitis. Methods: Between 2017 and 2020, we evaluated 230 women with vulvovaginal candidiasis and 400 asymptomatic. We obtained 130 positive cultures for Candida spp from vulvovaginitis and 94 asymptomatic. Yeasts were characterized by classical and molecular tests. Sensitivity to fluconazole and ketoconazole was evaluated by E-test. We used photodynamic light through blue LED, wavelengths between 450 to $470 \mathrm{~nm}$, power of $260 \mathrm{~mW}$, energy fluence of $270 \mathrm{~J} / \mathrm{cm}^{2}$, for 15 minutes over all colonies of Candida spp. Methylene blue (MB) at 450 $\mathrm{mg} / \mathrm{mL}, 2 \%$ gentian violet (VG) and $50 \mu \mathrm{M}$ curcumin (CR) were used in association or not with LED irradiation. Suspensions of Candida spp of $10^{6}$ $\mathrm{CFU} / \mathrm{mL}$, subjected to the different assays, were introduced in 96-well microplates, incubated for 48 hours at $35^{\circ} \mathrm{C}$ and the readings at $530 \mathrm{~nm}$. The samples were finally cultivated in Petri plates containing Sabouraud dextrose agar to assess the growth inhibition. All procedures were in triplicate. Results: $C$. albicans was prevalent in vulvovaginal candidiasis, however, we also isolated non-albicans species such as $C$. glabrata, C. tropicalis and C. parapsilosis.
\end{abstract}


There was a substantial reduction $(66.6 \%$ to $83.8 \%)$ of the CFU/mL of the isolates treated with FDT. Gentian violet at $2 \%$ alone reduced the growth of $\mathrm{CFU} / \mathrm{ml}$ of Candida spp from $69 \%$ to $75 \%$. Among isolates of vaginitis and asymptomatic carriers, after using FDT, we found a reduction in resistant phenotypes and DDS for fluconazole in percentages from $20 \%$ to $100 \%$ for $C$. albicans, from $50 \%$ to $100 \%$ C. glabrata, $33.3 \%$ to $100 \%$ C. parapsilosis and $100 \%$ C. tropicalis. For ketoconazole in the same isolates, there was a reduction in phenotypes with MIC $>16 \mu \mathrm{g} / \mathrm{mL}$ of up to $50 \%$ in $C$. albicans, $50 \%$ to $100 \%$ C. glabrata, $50 \%$ to $100 \%$ C tropicalis. Conclusions: PDT with MB, $\mathrm{GV}$ and $\mathrm{CR}$ revealed efficacy in vitro in reducing the growth of $C$. albicans and non-albicans, especially due to chronic recurrent vulvovaginitis.

\section{Keywords}

Photodynamic Therapy, Photosensitizers, Candida albicans, Species

Non-Albicans, Complicated Fungal Vulvovaginitis

\section{Introduction}

Three out of four women have at least one episode of vaginal candidiasis during their reproductive years, $40 \%$ of whom will experience a second episode and $5 \%$ of them will have recurrent vaginitis that is characterized by four or more episodes of vaginitis during one year, with clinical diagnosis and confirmation by culture [1] [2] [3]. Vulvovaginitis caused by Candida spp can be classified as uncomplicated (CVV), when they are manifested by sporadic or infrequent episodes, with mild or moderate symptoms, and complicated (CVVC), such as recurrent vulvovaginitis (CVVR) [4] [5] [6].

Vulvovaginal infection by Candida spp is diagnosed by clinical and epidemiological conditions, without which colonization cannot be distinguished from infection. About $20 \%$ to $30 \%$ of women have vaginal colonization by Candida spp and are asymptomatic [7]. It is accepted that $C$. albicans is responsible for 80 to $92 \%$ of cases of candidiasis vulvovaginal [8]. The clinical syndrome caused by non-albicans species can be indistinguishable from that caused by $C$. albicans [9]. Increased frequency of other species such as C. glabrata, C. tropicalis, C. parapsilosis, C. guilliermondii and $C$. krusei, among others, has occurred [10] [11]. Recurrences have been attributed to factors such as sexual transmission, hygiene habits, intestinal colonization, allergic and idiopathic causes. However, the epidemiological profile of women with recurrent idiopathic vulvovaginitis has not yet been established [12] [13].

Conventional treatments for fungal vulvovaginitis include antifungals such as ketoconazole, fluconazole and other azoles, but therapeutic failures are common, particularly in patients with $C$. glabrata vaginitis [10]. Fluconazole is a broad spectrum antifungal, with excellent therapeutic results for several Candida species, except for $C$. glabrata and $C$. krusei, as they have intrinsic resistance to this medication. C. glabrata vaginitis is considered the greatest challenge to the anti- 
fungals used [6] [14]. The indiscriminate use of broad spectrum antifungal agents has contributed to the increase in recurrent vaginitis, due to the increasing proportion of events caused by non-albicans species and often resistant to azole derivatives [15]. The continued and progressive intolerance to antifungals is a problem of extreme gravity and concern that encourages the design of new antifungal drugs and new therapeutic techniques.

Photodynamic therapy (PDT) consists of the use of a photo-sensitive component and an appropriate light source, representing an effective, promising and safe alternative in the treatment of fungal diseases, among others [16] [17] [18] [19] [20]. Studies have shown the susceptibility of Candida spp to PDT, however, studies on the susceptibility of strains of Candida resistant to fluconazole are restricted [19] [20] [21] [22] [23]. Some aspects related to the results of PDT on Candida spp in vitro still need to be better elucidated [19]-[24]. The efficacy of PDT associated with sensitizers such as methylene blue and toluidine blue is reported in the treatment of patients with candidiasis caused by fluconazole-resistant C. glabrata and C. albicans [17] [21] [22] [25].

Photodynamic therapy using methylene blue at a concentration of 250 to 400 $\mathrm{mg} / \mathrm{ml}$ promotes a reduction in the growth of $C$. albicans, occurring its complete eradication, in the oral cavity, when concentrations of 450 to $500 \mathrm{mg} / \mathrm{ml}$ of methylene blue are used [22]. A study evaluated in vitro, the action of $1 \%$ gentian violet dye associated with laser and observed an important effect of photodynamic therapy against Candida albicans [26]. The gentian violet solution has a potent antifungal activity against several species of Candida, such as C. albicans, C. glabrata and C. parapsilosis [27]. Martins et al. (2009), evaluated the antifungal activity of Curcumin in 23 strains of fungi in vitro and an inhibitory effect on several species of Candida spp, much more efficient than fluconazole [27]. Results from another study showed that blue LED associated with Curcumin proved to be effective in the photodynamic inactivation of $C$. albicans in vitro [28].

The present study aims to verify in vitro the synergistic effect of the combination of photodynamic light associated with sensitizers such as methylene blue, gentian violet or curcumin to inhibit the growth of Candida spp from complicated VVC and asymptomatic women.

\section{Materials and Methods}

\subsection{Study Population}

Microbial isolates were from of women with clinical suspicion of vulvovaginitis, coming from Basic Public Health Units, Private Offices and other Gynecology Services, and the study in question was developed in four years (2017-2020), together with the Laboratory of Mycology and the Department of Gynecology of Paulista School of Medicine/Federal University of São Paulo under the scientific opinion of the Research Ethics Committee $\mathrm{N}^{\circ}$ 5505. All participants signed an informed consent form (FICF). Financial resources and responsibility for re- 
search costs were borne by the researcher.

Were included in the study adult participants aged 18 to 65 years with chronic and/or recurrent vaginitis and asymptomatic women who attend for the collection of gynecological routine and oncotic colpocytology examination. Were excluded from the study pregnant women with diabetes mellitus, on corticotherapy, antibiotic therapy or hormone therapy, with immunosuppression, carriers of the human immunodeficiency virus (HIV), using an intrauterine device (IUD), or who used vaginal douches or spermicides.

\subsection{Collection, Isolation and Identification of Yeasts}

Vaginal secretion was collected with the help of a non-lubricated speculum from the ectocervix regions and from the bottom of the vagina using a swab moistened in a sterile saline solution. A total of 630 participants were evaluated, 230 clinically compatible with vulvovaginal candidiasis and 400 asymptomatic. The samples were seeded on Sabouraud dextrose agar media supplemented with chloramphenicol $(100 \mathrm{mg} / \mathrm{mL})$ and Chromagar Candida, obtaining 140 positive cultures from symptomatic women and 94 from asymptomatic women. From pure cultures, yeasts were identified using non-specific primers from the ITS1 and ITS4 regions, CALB1 and CALB2 for $C$. albicans, CGLAB1 and CGLAB2 for C. glabrata, CTR1 and CTR2 for C. tropicalis, and CPAR3 and CPAR2 for $C$. parapsilosis.

\subsection{Antifungigram}

For antifungal susceptibility tests, fluconazole and ketoconazole from the standard E-Test Kit (AB Biodisk, Solna, Sweden) were used. The isolates were cultivated on Sabouraud-dextrose agar (DIFCO), at a temperature of $37^{\circ} \mathrm{C}$, for a period of 48 hours, suspended in sterile saline solution according to a $0.5 \mathrm{McFar}-$ land scale and cultured in Petri dishes containing the solidified medium. The E-Test antimycotic strips, after a period of 15 minutes at room temperature, were added in contact with the seeding in agar. The reading of the MICs was made after 24 and 48 hours of incubation at $35^{\circ} \mathrm{C}$ following the edge of the ellipse until the lowest concentration on the E-Test strip. Inconsistent and contradictory readings or high minimum inhibitory concentration (MIC) values of the antifungal fluconazole were repeated, as instructed by AB Biodisk (1993). In addition to the isolated fungi, C. parapsilosis ATCC 22019 was included in each experiment for quality control in the verification of drug activity, since fluconazole MICs for this microorganism are previously known, according to Rex et al., 1996 [29] and NCCLS, CLSI [30] [31] [32] [33]. For ketoconazole there are no established breakpoints. Susceptibility criteria to fluconazole adopted: $\leq 8 \mu \mathrm{g} / \mathrm{ml}$ (Sensitive, S), 16 and $32 \mu \mathrm{g} / \mathrm{ml}$ (susceptibility-dependent-dose, SDD), $\geq 64 \mu \mathrm{g} / \mathrm{ml}$ (Resistant, R) [33].

\subsection{Use of Photodynamic Light (PL) and Photosensitizing Dyes}

Irradiation source consisting of LED devices (Light Emitting Diode) type 
adapted photopolymerizers, with blue light emitting diodes, wavelengths between 450 and $470 \mathrm{~nm}$, at the power of $260 \mathrm{~mW}$, dosimetry $270 \mathrm{~J} / \mathrm{cm}^{2}$, during periods of time of 15 minutes was used in the research. The incident light was oriented perpendicularly at a distance of $15 \mathrm{~cm}$ and directed from top to bottom, over all Candida spp colonies, before and after antifungigram, seeking to evaluate in vitro the effectiveness of (PL) in the viability of Candida spp inactivation. Photosensitizers such as methylene blue, gentian violet and curcumin, associated or not with LED light irradiation, were used at concentrations of 450 $\mathrm{mg} / \mathrm{ml}(\mathrm{MB}), 2 \%(\mathrm{GV})$ and $50 \mu \mathrm{M}(\mathrm{CR})$, respectively. Thus, the different groups were classified: single treatment: LED, GV, MB, CR; treatment in combination: $\mathrm{LED}+\mathrm{GV}, \mathrm{LED}+\mathrm{MB}, \mathrm{LED}+\mathrm{CR}$; and control $(\mathrm{K})$ without treatment.

Candida spp cultures, after tests with LED and photosensitizing dyes, were inoculated in $5 \mathrm{~mL}$ of sterilized peptone saline (SPS), being homogenized in a vortex, to obtain concentrations of $106 \mathrm{CFU} / \mathrm{mL}$, measured in a spectrophotometer, with $76 \%$ transmittance at $530 \mathrm{~nm}$. Suspensions from different groups were introduced separately into 96-well microplates and then subjected to different treatments. Such Candida spp growths, at concentrations of $10^{-1}$ and $10^{-2}$ $\mathrm{mL}$, were seeded by the spread-plate method in Petri dishes containing Sabouraud-dextrose agar and incubated under aerobic conditions for 48 hours at a temperature of $35^{\circ} \mathrm{C}$. Subsequently, the counts of the respective Candida spp colonies were performed.

Means resulting from the measurements of the procedures performed with all isolates and treatments were then calculated. The interpretation of the results was based on the MIC values recommended by CLSI M27 A2, CLSI M27 S3, CLSI M27 S4 and NCCLS [30]-[36] Documents. All tests were developed in triplicate. Fluconazole susceptibility criteria: $\leq 8 \mu \mathrm{g} / \mathrm{ml}$ (Susceptible, S), 16 and 32 $\mu \mathrm{g} / \mathrm{ml}$ (Susceptible-dose-dependent, DDS), $\geq 64 \mu \mathrm{g} / \mathrm{ml}$ (Resistant, R) [33].

\section{Results}

From the material collected from patients with complicated vaginitis, 120 cultures were obtained (111 chronic and 9 recurrent), 10 from patients with sporadic vaginitis and 94 from asymptomatic women, making a total of 224 positive cultures for Candida spp (Table 1). Of these isolates, 181 (80.8\%) were identified as C. albicans, 14 (6.25\%) C. glabrata, 13 (5.8\%) C. tropicalis and 16 (7.15\%) C. parapsilosis. Among the 9 patients with recurrent vaginitis, the prevalence of non-albicans species was observed, being 5 C. glabrata (55.5\%), 2 C. albicans (22.25\%) and 2 C. tropicalis (22.25\%).

Referring to the microbial growth, in Table 2 we observe a marked reduction in the number of colonies of all Candida species after treatment with LED + GV, LED + MB, LED + CR and little inhibition with LED, MB, CR used alone. Gentian violet at a concentration of $2 \%$ substantially inhibited the growth of Candida spp.

After analyzing the susceptibility profile of Candida species to fluconazole 
Table 1. Number of Candida species identified from chronic and recurrent vaginitis, asymptomatic and sporadic participants.

\begin{tabular}{ccccc}
\hline Species & Chronic and recurrent & Asymptomatic & Sporadic & Total \\
& $\mathrm{N}$ & $\mathrm{n}$ & $\mathrm{n}$ & $\mathrm{N}$ \\
\hline C. albicans & 102 & 72 & 7 & 181 \\
C. tropicalis & 3 & 10 & 0 & 13 \\
C. parapsilosis & 7 & 8 & 1 & 16 \\
C. glabrata & 8 & 4 & 2 & 14 \\
Total & 120 & 94 & 10 & 224 \\
\hline
\end{tabular}

Table 2. Average of CFU/ml Candida spp counts $48 \mathrm{~h}$ after using photodynamic light with GV, MB, CR, or LED, GV, MB and CR photosensitizers alone. Percentages of colony reduction compared to the control group $(\mathrm{K})$ are superscripted in parentheses.

\begin{tabular}{ccccccccc}
\hline Species & K & LED & LED + GV & LED + MB & LED + CR & GV & MB & CR \\
\hline Ca (181) & 6.12 & $6.07_{(0.8)}$ & $1.36_{(77.7)}$ & $2.12_{(66.6)}$ & $1.12_{(81.7)}$ & $1.84_{(70)}$ & $6.02_{(1.7)}$ & $5.58_{(8.9)}$ \\
Ct (13) & 5.92 & $5.80_{(2.0)}$ & $1.04_{(82.5)}$ & $1.96_{(66.9)}$ & $1.02_{(83.8)}$ & $1.48_{(75)}$ & $5.58_{(5.8)}$ & $5.02_{(5.3)}$ \\
Cp (16) & 4.98 & $4.86_{(2.4)}$ & $1.10_{(78)}$ & $1.65_{(66.9)}$ & $1.24_{(75.2)}$ & $1.39_{(72)}$ & $4.50_{(9.7)}$ & $4.26_{(15.5)}$ \\
Cg (14) & 5.87 & $5.72_{(2.5)}$ & $1.31_{(77.7)}$ & $1.47_{(75)}$ & $1.25_{(78.7)}$ & $1.82_{(69)}$ & $5.57_{(5.1)}$ & $4.23_{(27.9)}$ \\
\hline
\end{tabular}

Mean values of CFU/ml Candida spp counts $(\mathrm{n}=224)$ expressed in $(\log 10)$. Groups: without treatment administration (control group, $\mathrm{K}$ ) and all groups, after using photodynamic light plus photosensitizers and isolated agents (LED, GV, MB and CR). $\mathrm{Ca}=C$. albicans, $\mathrm{Ct}=C$. tropicalis, $\mathrm{Cp}=C$. parapsilosis, $\mathrm{Cg}=C$. glabrata .

in vitro (Table 3 ) compared to the use of photodynamic light and $M B, G V$ and CR sensitizers (Tables 4-6), a reduction in the number of resistant isolates was observed to the antifungal, mainly in resistant species and susceptible-dose-dependent (SDD) from women with chronic, recurrent and sporadic vulvovaginitis.

After treatment with photodynamic light and GV photosensitizing, there was a reduction in the percentage of resistant isolates from women with vulvovaginitis (C. albicans, 42.8\%; C. tropicalis, 100\%; C. glabrata, 75\%) and asymptomatic (C. glabrata, 50\%), as shown in Table 4. There was also a reduction in the percentage of SDD isolates, originating from vulvovaginitis (C. parapsilosis, $33.3 \%$; C. glabrata, 100\%) and asymptomatic (C. albicans, 40\%; C. tropicalis, 100\%).

Treatment with photodynamic light and methylene blue intensified the susceptibility to fluconazole, decreasing the percentage of resistant isolates from women with vulvovaginitis (C. albicans, $28 \%$; C. glabrata, $75 \%$ ) and asymptomatic (C. glabrata, 50\%), according to Table 5. The DDS isolates also had a reduction in isolates from women with vulvovaginitis (C. glabrata, 100\%) and asymptomatic (C. albicans, 20\%; C. tropicalis, 100\%; C. parapsilosis, 100\%).

The use of curcumin and photodynamic light caused a decrease in the resistant profiles among isolates of vulvovaginites (C. albicans, $57.7 \%$; C. tropicalis, 100\%, C. glabrata, 100\%) and asymptomatic (C. glabrata, 100\%), Table 6. 
Table 3. In vitro fluconazole susceptibility profile of Candida spp isolated from asymptomatic women (a) and vulvovaginitis with chronic, recurrent and sporadic (v).

\begin{tabular}{ccccccc}
\hline \multirow{2}{*}{ Species } & \multicolumn{2}{c}{ Resistant } & \multicolumn{2}{c}{ DDS } & \multicolumn{2}{c}{ Sensitive } \\
\cline { 2 - 7 } & $\mathrm{n}$ & $\%$ & $\mathrm{n}$ & $\%$ & $\mathrm{n}$ & $\%$ \\
\hline C. albicans $_{a}(\mathrm{n}=72)$ & 0 & 0 & 5 & 6.9 & 67 & 92.9 \\
C. albicans $_{\mathrm{v}}(\mathrm{n}=109)$ & 7 & 6.4 & 6 & 5.6 & 96 & 88 \\
C. tropicalis $_{\mathrm{a}}(\mathrm{n}=10)$ & 0 & 0 & 1 & 10 & 9 & 90 \\
C. tropicalis $_{\mathrm{v}}(\mathrm{n}=03)$ & 1 & 33.3 & 0 & 0 & 2 & 66.7 \\
C. parapsilosis $_{a}(\mathrm{n}=8)$ & 0 & 0 & 1 & 12.5 & 7 & 87.5 \\
C. parapsilosis $(\mathrm{n}=08)$ & 0 & 0 & 3 & 37.5 & 5 & 62.5 \\
C. glabrata $_{\mathrm{v}}(\mathrm{n}=4)$ & 2 & 50 & 1 & 25 & 1 & 25 \\
C. glabrata $_{\mathrm{v}}(\mathrm{n}=10)$ & 4 & 40 & 1 & 10 & 5 & 50 \\
Total $(224)^{14}$ & 14 & 6.25 & 18 & 8 & 192 & 85.75 \\
\hline
\end{tabular}

Table 4. Susceptibility to fluconazole in vitro of Candida spp isolated from asymptomatic (a) and with vulvovaginitis $(v)$ after photodynamic light with VG. Percentages of reduction in resistant isolates are expressed in italics, compared to the values expressed in $\mathrm{Ta}$ ble 3.

\begin{tabular}{ccccccc}
\hline \multirow{2}{*}{ Species } & \multicolumn{2}{c}{ Resistant } & \multicolumn{2}{c}{ SDD } & \multicolumn{2}{c}{ Sensitive } \\
\cline { 2 - 7 } & $\mathrm{n}$ & $\%$ & $\mathrm{n}$ & $\%$ & $\mathrm{n}$ & $\%$ \\
\hline C. albicans $_{a}(\mathrm{n}=72)$ & 0 & 0 & $3(40 \%)$ & 4.3 & 69 & 95.7 \\
C. albicans $_{V}(\mathrm{n}=109)$ & $4(42.8 \%)$ & 3.7 & 6 & 5.6 & 99 & 90.7 \\
C. tropicalis $_{a}(\mathrm{n}=10)$ & 0 & 0 & $0_{(100 \%)}$ & 0 & 10 & 100 \\
C. tropicalis $_{V}(\mathrm{n}=3)$ & $0_{(100 \%)}$ & 0 & 0 & 0 & 3 & 100 \\
C. parapsilosis $_{a}(\mathrm{n}=8)$ & 0 & 0 & 1 & 12.5 & 7 & 87.5 \\
C. parapsilosis $_{V}(\mathrm{n}=8)$ & 0 & 0 & $2(33.3)$ & 25 & 6 & 75 \\
C.glabrata $_{(}(\mathrm{n}=4)$ & $1_{(50 \%)}$ & 25 & 1 & 25 & 2 & 50 \\
C. glabrata $_{V}(\mathrm{n}=10)$ & $1_{(75 \%)}$ & 10 & $0_{(100 \%)}$ & 0 & 9 & 90 \\
$\operatorname{Total~}(224)$ & 6 & 2.7 & 13 & 5.8 & 205 & 91.5 \\
\hline
\end{tabular}

Reduction in the percentage of DDS isolates from vulvovaginitis (C. parapsilosis, 66.7\%; C. glabrata, 100\%) and asymptomatic (C. albicans, 60\%; C. tropicalis, $100 \%$; C. glabrata, 100\%) was also observed.

Regarding ketoconazole, six isolates, two C. albicans, two C. tropicalis and two C. glabrata, four from patients with chronic or recurrent vaginitis and two from asymptomatic women, showed high MICs $>16 \mu \mathrm{g} / \mathrm{mL}$ before submitted to the LED associated with photosensitizers. We did not obtain MIC $>16 \mu \mathrm{g} / \mathrm{mL}$ in $C$. parasilosis. After undergoing LED $+\mathrm{MB}$, we observed that there was a $50 \%$ reduction in MICs $>16 \mu \mathrm{g} / \mathrm{mL}$ in C. tropicalis, C. glabrata.

Treated under the action of LED + GV, we found that there was a $50 \%$ reduction in MICs $>16 \mu \mathrm{g} / \mathrm{mL}$ in C. albicans, C. tropicalis, C. glabrata. After LED + 
Table 5. Susceptibility to fluconazole in vitro from Candida spp isolated from asymptomatic (a) and with vulvovaginitis ( $v$ ) after PL with MB. Percentages of reduction in resistant and SDD isolates compared to the values expressed in Table 3.

\begin{tabular}{ccccccc}
\hline \multirow{2}{*}{ Species } & \multicolumn{2}{c}{ Resistant } & \multicolumn{2}{c}{ DDS } & \multicolumn{2}{c}{ Sensitive } \\
\cline { 2 - 7 } & $\mathrm{n}$ & $\%$ & $\mathrm{n}$ & $\%$ & $\mathrm{n}$ & $\%$ \\
\hline C. albicans $_{V}(\mathrm{n}=109)$ & $5(28 \%)$ & 4.5 & 6 & 5.6 & 98 & 89.9 \\
C. tropicalis $_{V}(\mathrm{n}=03)$ & 1 & 33.3 & 0 & 0 & 2 & 66.7 \\
C. parasilosis $_{V}(\mathrm{n}=08)$ & 0 & 0 & 3 & 37.5 & 5 & 62.5 \\
C. glabrata $_{V}(\mathrm{n}=10)$ & $1_{(75 \%)}$ & 10 & $0_{(100 \%)}$ & 0 & 9 & 90 \\
C. albicans $_{a}(\mathrm{n}=72)$ & 0 & 0 & $4_{(20 \%)}$ & 5.5 & 68 & 94.5 \\
C. tropicalis $_{a}(\mathrm{n}=10)$ & 0 & 0 & $0_{(100 \%)}$ & 0 & 10 & 100 \\
C. parasilosis $_{a}(\mathrm{n}=8)$ & 0 & 0 & $0_{(100 \%)}$ & 0 & 8 & 100 \\
C. glabrata $_{a}(\mathrm{n}=4)$ & $1(50 \%)$ & 25 & 1 & 25 & 2 & 50 \\
Total $(224)$ & 8 & 3.5 & 14 & 6.25 & 202 & 90.25 \\
\hline
\end{tabular}

Table 6. Susceptibility to fluconazole in vitro of Candida spp isolated from asymptomatic $(a)$ and with vulvovaginitis $(v)$ after PL with CR. Percentages of reduction in resistant and SDD isolates compared to the values expressed in Table 3.

\begin{tabular}{|c|c|c|c|c|c|c|}
\hline \multirow{2}{*}{ Species } & \multicolumn{2}{|c|}{ Resistant } & \multicolumn{2}{|c|}{ SDD } & \multicolumn{2}{|c|}{ Sensitive } \\
\hline & $\mathrm{n}$ & $\%$ & $\mathrm{n}$ & $\%$ & $\mathrm{n}$ & $\%$ \\
\hline C. albicans $_{a}(\mathrm{n}=72)$ & 0 & 0 & $4_{(20 \%)}$ & 5.5 & 68 & 94.5 \\
\hline C. albicans $_{V}(\mathrm{n}=109)$ & $5(28 \%)$ & 4.5 & 6 & 5.6 & 98 & 89.9 \\
\hline C. tropicalis $_{a}(\mathrm{n}=10)$ & 0 & 0 & $0_{(100 \%)}$ & 0 & 10 & 100 \\
\hline C. tropicalis $_{V}(\mathrm{n}=3)$ & 1 & 33.3 & 0 & 0 & 2 & 66.7 \\
\hline C. parapsilosis $a(\mathrm{n}=8)$ & 0 & 0 & $0_{(100 \%)}$ & 0 & 8 & 100 \\
\hline C. parapsilosis $(\mathrm{n}=8)$ & 0 & 0 & 3 & 37.5 & 5 & 62.5 \\
\hline C. glabrata $_{a}(\mathrm{n}=4)$ & $1_{(50 \%)}$ & 25 & 1 & 25 & 2 & 50 \\
\hline C. $\operatorname{glabrata}_{V}(\mathrm{n}=10)$ & $1_{(75 \%)}$ & 10 & $0_{(100 \%)}$ & 0 & 9 & 90 \\
\hline Total (224) & 8 & 3.5 & 14 & 6.25 & 202 & 90.25 \\
\hline
\end{tabular}

CR, here was a $100 \%$ reduction in MICs $>16 \mu \mathrm{g} / \mathrm{mL}$ in C. tropicalis, C. glabrata.

Two $C$. albicans isolates were resistant to fluconazole after the three photodynamic procedures administered (LED + MB, LED + GV and LED + CR) and with high MICs $>16 \mu \mathrm{g} / \mathrm{mL}$ for ketoconazole. Both of these isolates originated from secretions collected from patients with recurrent vaginitis. The trailing phenomenon was also registered in these two $C$. albicans isolates and in two $C$. tropicalis.

\section{Discussion}

Among women participating in this study, asymptomatic and affected by chronic or recurrent vaginitis, we found high percentages of non-albicans species, in 
acordance with what was also observed in other studies [4] [11]. We identified isolates with a resistant and dose-dependent profile to fluconazole, both among C. albicans and non-albicans species, coming from materials collected from patients with chronic and recurrent vaginitis such as Candida albicans (13, $11.92 \%)$, C. tropicalis (1, 33.3\%), C. parapsilosis (3, 60\%), C. glabrata (5, 50\%), and those obtained from asymptomatic women, such as Candida albicans (5, 6.94\%), C. tropicalis (1, 10\%), C. parapsilosis (1, 12.5\%), C. glabrata (3.75\%). We also recorded MIC $>16 \mu \mathrm{g} / \mathrm{mL}$ in relation to ketoconazole between $C$. albicans and non-albicans species. Resistance to antifungal treatments is also frequently observed in other studies [10] [25] [37] [38]. Non-albicans species, in addition to being frequent in complicated vulvovaginitis, have shown high levels of resistance to conventional antifungal agents, which was also verified in this research.

Our work has evidenced C. glabrata as an etiological agent resistant to antifungal agents ordinarily listed in the treatment of vaginitis, emphasizing that PDT reduced or even blocked in vitro the development of colonies of this agent, which is considered yeast associated with chronic vaginitis and/or recurrence of vaginitis and nowadays, it constitutes a considerable obstacle to the therapeutic efficacy of widely used antifungals, an event also registered in other studies [6] [10] [14] [25]. Candida glabrata is often associated with a chronic evolution, recurrence in vulvovaginitis and high resistance to antifungal agents. LED alone did not show homogeneous results for yeast in this study.

With respect to $C$. albicans, studies on photodynamic (PD) light and methylene blue also report similar results regarding the substantial blockage in the growth of colonies of this particular yeast [22] [39] [40]. In this study, the synergistic use of PD light and methylene blue with increased efficacy in blocking the growth of colonies of the tested yeast species such as C. glabrata, C. parapsilosis, C. tropicalis and C. albicans.

The PD light associated with methylene blue showed important reductions in the number of colonies resistant to fluconazole or ketoconazole (MICs $>16$ $\mu \mathrm{g} / \mathrm{mL}$ ) and also in the reduction of resistant phenotypes, when compared to values recorded before treatment. A study with PD light and methylene blue found its use viable to inhibit $C$. albicans species from infection [41], which was also observed in this research, including in relation to other Candida species. These findings suggest PD light with methylene blue as a promising therapeutic alternative for fungal infections, including vulvovaginitis, especially in relation to non-albicans species, and further studies should be prospected to prove their in vivo efficacy. Other research on PD light and methylene blue treatments used for fluconazole resistant yeasts such as $C$. glabrata and $C$. albicans also describes similar results [21] [22] [25] [42]. Non-albicans species, many times, show resistance to conventional antifungal treatments [43] [44].

Investigations have shown the efficiency of gentian violet used alone, in terms of blocking the growth of $C$. albicans and non-albicans colonies. Gentian violet in $1 \%$ concentration was effective with regard to the total blockade in the growth of $C$. albicans, both in its use as a single agent and in association with light [26]. 
In our research, we also found the inhibitory activity $C$. albicans and non albicans species with PD light by LED and gentian violet solution $2 \%$ in both the separate use or as jointly.

Martins et al. in 2009 and Freitas in 2015 observed that curcumin, when compared to fluconazole, showed antifungal activity with greater inhibitory potential, on C. albicans and non-albicans species, such as C. tropicalis, C. parapsilosis and C. glabrata [27] [45]. In our work, however, it was only when we used curcumin together with LED light irradiation that we obtained antifungal efficacy, blocking the growth of $C$. albicans and non-albicans yeast colonies. We recorded only a mild antifungal effect of curcumin when used alone. However, its use associated with PD light revealed a good synergism in vitro, markedly inhibiting the growth of $C$. albicans and non-albicans colonies. Similar findings were also obtained in another investigation [24] [46].

We emphasize in our study, when using only LED or photosensitizers alone, we did not obtain reduction in the growth of Candida colonies, both $C$. albicans and non-albicans, resistant to fluconazole and with MIC $>16 \mu \mathrm{g} / \mathrm{mL}$ for ketoconazole, except for the gentian violet solution $2 \%$, which actually showed antifungal activity, both in PDT and as a single agent. Other investigations have also found antifungal activity of gentian violet used in isolation [43] [47] [48] [49] [50].

We call attention that associations of photosensitizers with LED seem to be impactful with regard to blocking the growth of colonies of $C$. albicans or non-albicans species and the PDT procedure, after more studies and clinical trials, may constitute in future an important basis for the treatment of vulvovaginitis, particularly in chronic or recurrent cases, considering that it can represent efficient, low-cost treatment, without major side effects. In the specific case of gentian violet, we would still consider the practicality of representing possibly effective antifungal agent, potentially effective, having greater synergism when used with LED irradiation.

\section{Conclusions}

We emphasize that all 224 Candida spp isolates were submitted to photodynamic light with methylene blue, gentian violet and curcumin photosensitizers. We observed a reduction in the percentage of UFC/mL and of resistant and SDD phenotypes to fluconazole and to ketoconazole MICs $>16 \mu \mathrm{g} / \mathrm{mL}$. Photodynamic therapy proved to be promising and effective in vitro, with regard to the significant reduction of fungal colonies of $C$. albicans and non-albicans species, including $C$. tropicalis and mainly $C$. glabrata, yeast species associated with severe cases of chronic recurrent vulvovaginitis. Our investigation was developed "In Vitro", but its results may serve as parameters in future to in vitro and in vivo researches. New therapeutic solutions, more efficient, less aggressive, with minor or without organic toxicity, with treatments based on a short period of time, and that do not provoke the selection of new resistant and potentially aggravating 
microbial strains, are required in fungal vulvovaginitis mainly for complicated cases. In these aspects, PDT could be an interesting tool, used as a single treatment or in addition to antifungal agents, for future studies involving Candida vulvovaginitis chronicity and recurrence especially to ways for gynecological clinic practice improvement.

\section{Conflicts of Interest}

The authors declare no conflicts of interest regarding the publication of this paper.

\section{References}

[1] Hong, E., Dixit, S., Fidel, P.L., Bradford, J. and Fischer, G. (2014) Vulvovaginal Candidiasis as a Chronic Disease: Diagnostic Criteria and Definition. Journal of Lower Genital Tract Disease, 18, 31-38. https://doi.org/10.1097/LGT.0b013e318287aced

[2] Hurley, R. and de Louvois, J. (1979) Candida Vaginitis. Postgraduate Medical Journal, 55, 645-647. https://doi.org/10.1136/pgmj.55.647.645

[3] Hurley, R. (1981) Recurrent Candida Infection. Clinics in Obstetrics and Gynaecology, 8, 209-214. https://doi.org/10.1016/S0306-3356(21)00060-1

[4] Feuerschuette, O.H.M., Silveira, S.K., Feuerschuette, I., Corrêa, T., Grando, L. and Trepani, A. (2010) Recurrent Vaginal Candidiasis: Clinical Management. Femina, 38, 31-36. http://files.bvs.br/upload/S/0100-7254/2010/v38n1/a005.pdf

[5] Bernstein, J.A. and Seidu, L. (2015) Chronic Vulvovaginal Candida Hypersensitivity: An Underrecognized and Undertreated Disorder by Allergists. Allergy \& Rhinology, 6, 44-49. https://doi.org/10.2500/ar.2015.6.0113

[6] Sobel, J.D. (1998) Key Note Lecture Review Article Vulvovaginitis Due to Candida Glabrata. An Emerging Problem. Mycoses, 41, 18-22.

https://doi.org/10.1111/j.1439-0507.1998.tb00594.x

[7] Ribeiro, M.A., Dietze, R., Paula, C.R., Da Matta, D.A. and Colombo, A.L. (2001) Susceptibility Profile of Vaginal Yeast Isolates from Brazil. Mycopathologia, 151, 5-10. https://doi.org/10.1023/A:1010909504071

[8] Corrêa, P. dos R., David, P.R. dos S., Peres, N.P., da Cunha, K.C. and de Almeida, M.T.G. (2009) Caracterização Fenotípica de Leveduras Isoladas da Mucosa Vaginal em Mulheres Adultas. Revista Brasileira de Ginecologia e Obstetrícia, 31, 177-181. https://doi.org/10.1590/S0100-72032009000400004

[9] Ferrazza, M.H.S.H., Maluf, M.L.F., Consolaro, M.E.L., Shinobu, C.S., Svidzinski, T.I.E. and Batista, M.R. (2005) Caracterização de Leveduras Isoladas da Vagina e sua Associação com Candidíase Vulvovaginal em duas Cidades do Sul do Brasil. Revista Brasileira de Ginecologia e Obstetrícia, 27, 58-63. https://doi.org/10.1590/S0100-72032005000200003

[10] Sobel, S.D. (1997) Vaginitis. The New England Journal of Medicine, 337, 1896-1903. https://doi.org/10.1056/NEJM199712253372607

[11] Diba, K., Namaki, A., Ayatolahi, H. and Hanifian, H. (2012) Rapid Identification of Drug Resistant Candida Species Causing Recurrent Vulvovaginal Candidiasis. Medical Mycology Journal, 53, 193-198. https://doi.org/10.3314/mmj.53.193

[12] Spinillo, A., Pizzoli, G., Colonna, L., Nicola, S., De Seta, F. and Guaschino, S. (1994) Epidemiologic Characteristics of Women with Idiopathic Recurrent Vulvovaginal 
Candidiasis. International Journal of Gynecology \& Obstetrics, 44, 192. https://doi.org/10.1016/0020-7292(94)90096-5

[13] Hilton, E., Chandrasekaran, V., Rindos, P. and Isenberg, H.D. (1995) Association of Recurrent Candidal Vaginitis with Inheritance of Lewis Blood Group Antigens. The Journal of Infectious Diseases, 172, 1616-1619.

https://doi.org/10.1093/infdis/172.6.1616

[14] Espinel-Ingroff, A., Pfaller, M., Erwin, M.E. and Jones, R.N. (1996) Interlaboratory Evaluation of Etest Method for Testing Antifungal Susceptibilities of Pathogenic Yeasts to Five Antifungal Agents by Using Casitone Agar and Solidified RPMI 1640 Medium with 2\% Glucose. Journal of Clinical Microbiology, 34, 848-852. https://doi.org/10.1128/jcm.34.4.848-852.1996

[15] MacNeill, C. and Carey, J.C. (2001) Recurrent Vulvovaginal Candidiasis. Current Womens Health Reports, 1, 31-35.

[16] Mizuno, K., Zhiyentayev, T., Huang, L., Khalil, S., Nasim, F., Tegos, G.P., Gali, H., Jahnke, A., Wharton, T. and Hamblin, M.R. (2011) Antimicrobial Photodynamic Therapy with Functionalized Fullerenes: Quantitative Structure-Activity Relationships. Journal of Nanomedicine and Nanotechnology, 2, Article No. 109.

https://doi.org/10.4172/2157-7439.1000109

[17] Lyon, J.P., de Pedroso e Silva Azevedo, C.M., Moreira, L.M., de Lima, C.J. and de Resende, M.A. (2011) Photodynamic Antifungal Therapy against Chromoblastomycosis. Mycopathologia, 172, 293-297. https://doi.org/10.1007/s11046-011-9434-6

[18] Henderson, B.W. and Dougherty, T.J. (1992) How Does Photodynamic Therapy Work? Photochemistry and Photobiology, 55, 145-157.

https://doi.org/10.1111/j.1751-1097.1992.tb04222.x

[19] Baltazar, L.M., Ray, A., Santos, D.A., Cisalpino, P.S., Friedman, A.J. and Nosanchuk, J.D. (2015) Antimicrobial Photodynamic Therapy: An Effective Alternative Approach to Control Fungal Infections. Frontiers in Microbiology, 6, Article No. 202. https://doi.org/10.3389/fmicb.2015.00202

[20] Donnelly, R.F., McCarron, P.A., Tunney, M.M. and David Woolfson, A. (2007) Potential of Photodynamic Therapy in Treatment of Fungal Infections of the Mouth. Design and Characterisation of a Mucoadhesive Patch Containing Toluidine Blue O. Journal of Photochemistry and Photobiology B: Biology, 86, 59-69. https://doi.org/10.1016/j.jphotobiol.2006.07.011

[21] Jackson, Z., Meghji, S., MacRobert, A., Henderson, B. and Wilson, M. (1999) Killing of the Yeast and Hyphal Forms of Candida albicans Using a Light-Activated Antimicrobial Agent. Lasers in Medical Science, 14, 150-157. https://doi.org/10.1007/s101030050037

[22] Teichert, M.C., Jones, J.W., Usacheva, M.N. and Biel, M.A. (2002) Treatment of Oral Candidiasis with Methylene Blue-Mediated Photodynamic Therapy in an Immunodeficient Murine Model. Oral Surgery, Oral Medicine, Oral Pathology, Oral Radiology, and Endodontics, 93, 155-160. https://doi.org/10.1067/moe.2002.120051

[23] Bliss, J.M., Bigelow, C.E., Foster, T.H. and Haidaris, C.G. (2004) Susceptibility of Candida Species to Photodynamic Effects of Photofrin. Antimicrobial Agents and Chemotherapy, 48, 2000-2006. https://doi.org/10.1128/AAC.48.6.2000-2006.2004

[24] Andrade, M.C., Ribeiro, A.P.D., Dovigo, L.N., Brunetti, I.L., Giampaolo, E.T., Bagnato, V.S. and Pavarina, A.C. (2013) Effect of Different Pre-Irradiation Times on Curcumin-Mediated Photodynamic Therapy against Planktonic Cultures and Biofilms of Candida spp. Archives of Oral Biology, 58, 200-210.

https://doi.org/10.1016/j.archoralbio.2012.10.011 
[25] Dovigo, L.N., Pavarina, A.C., De Oliveira Mima, E.G., Giampaolo, E.T., Vergani, C.E. and Bagnato, V.S. (2011) Fungicidal Effect of Photodynamic Therapy against Fluconazole-Resistant Candida albicans and Candida glabrata. Mycoses, 54, 123-130. https://doi.org/10.1111/j.1439-0507.2009.01769.x

[26] Pinheiro, R.C.D.Q., Peixoto, M.S., Ribeiro, I.L.A., Gomes, D.Q. de C., Pereira, M. do S.V. and De Moura Netto, C. (2018) Efeito Fotossenssibilizador in Vitro da Violeta de Genciana na Terapia Fotodinâmica sobre Candida albicans. Revista Família, Ciclos de Vida e Saúde no Contexto Social, 6, 158-165.

https://doi.org/10.18554/refacs.v6i2.2810

[27] Martins, C.V.B., Da Silva, D.L., Neres, A.T.M., Magalhães, T.F.F., Watanabe, G.A., Modolo, L. V., Sabino, A.A., De Fátima, Â. and De Resende, M.A. (2009) Curcumin as a Promising Antifungal of Clinical Interest. Journal of Antimicrobial Chemotherapy, 63, 337-339. https://doi.org/10.1093/jac/dkn488

[28] Alves, O.A. (2011) Avaliação Da Eficiência Do Diodo Emissor de Luz (LED) Emitindo Em $460 \mathrm{~nm}$ Associado à Curcumina na Fotossensibilização Letal de Candida albicans e de Aggregatibacter actinomycetemcomitans. Estudo in Vitro. Universidade Federal de Minas, Belo Horizonte.

https://repositorio.ufmg.br/bitstream/1843/BUOS-8NWGAV/1/disserta opdf 1 . pdf

[29] Rex, J.H., Pfaller, M.A., Lancaster, M., Odds, F.C., Bolmstrom, A. and Rinaldi, M.G. (1996) Quality Control Guidelines for National Committee for Clinical Laboratory Standards-Recommended Broth Macrodilution Testing of Ketoconazole and Itraconazole. Journal of Clinical Microbiology, 34, 816-817. https://doi.org/10.1128/jcm.34.4.816-817.1996

[30] Rodríguez-Tudela, J.L., Barchiesi, F., Bille, J., Chryssanthou, E., Cuenca-Estrella, M., Denning, D., Donnelly, J.P., Dupont, B., Fegeler, W., Moore, C., Richardson, M. and Verweij, P.E. (2003) Method for the Determination of Minimum Inhibitory Concentration (MIC) by Broth Dilution of Fermentative Yeasts. Clinical Microbiology and Infection, 9, 1-8. https://doi.org/10.1046/j.1469-0691.2003.00789.x

[31] Clinical Laboratory Standards Institute (2012) Reference Method for Broth Dilution Antifungal Susceptibility Testing of Yeast. Clinical and Laboratory Standards Institute, Annapolis Junction, 32.

[32] Rex, J.H., Alexander, B.D., Andes, D., Arthington-Skaggs, B., Brown, S.D., Chaturvedi, V., Ghannoum, M.A., Espinel-Ingroff, A., Knapp, C.C., Ostrosky-Zeichner, L., Pfaller, M.A., Sheehan, D.J. and Walsh, T.J. (2008) Reference Method for Broth Dilution Antifungal Susceptibility Testing of Yeasts: Approved Standard, Third Edition, Clinical and Laboratory Standards Institute, Annapolis Junction.

[33] Barry, A.L. and Brown, S.D. (1996) Fluconazole Disk Diffusion Procedure for Determining Susceptibility of Candida Species. Journal of Clinical Microbiology, 34, 2154-2157. https://doi.org/10.1128/jcm.34.9.2154-2157.1996

[34] Clinical and Laboratory Standards Institute (2017) M38-A: Reference Method for Broth Dilution Antifungal Susceptibility Testing of Yeasts. Clinical and Laboratory Standards Institute, Annapolis Junction.

[35] Clinical and Laboratory Standards Institute (2008) M27-S3: Reference Method for Broth Dilution Antifungal Susceptibility Testing of Yeasts; Third Informational Supplement. Clinical and Laboratory Standards Institute, Annapolis Junction, 28.

[36] Clinical and Laboratory Standards Institute (2012) M27-S4: Reference Method for Broth Dilution Antifungal Susceptibility Testing of Yeasts; Fourth Informational Supplement. Clinical and Laboratory Standards Institute, Annapolis Junction. 
[37] Shiozawa, P., Cechi, D., Figueiredo, M.A.P., Sekiguchi, L.T. and Lima, S.M.R.R. (2007) Tratamento da Candidíase Vaginal Recorrente: Revisão Atualizada. Arquivos Médicos dos Hospitais e da Faculdade de Ciências Médicas da Santa Casa de São Paulo, 52, 48-50.

https://arquivosmedicos.fcmsantacasasp.edu.br/index.php/AMSCSP/article/view/42 $\underline{1 / 474}$

[38] Boatto, H.F., Girão, M.J.B.C., Francisco, E.C., Machado, A.P., de Moraes, M.S. and Fischman, O. (2016) Susceptibility to Fluconazole and Ketoconazole of Candida spp. Isolated from Primary and Episodic Vulvovaginites by E-Test (São Paulo, SP, Brazil). Open Journal of Obstetrics and Gynecology, 6, 689-697.

https://doi.org/10.4236/ojog.2016.612086

[39] Oliveira, B.P. de, Lins, C.C. dos S.A., Diniz, F.A., Melo, L.L. and Castro, C.M.M.B. de. (2014) In Vitro Antimicrobial Photoinactivation with Methylene Blue in Different Microorganisms. Brazilian Journal of Oral Sciences, 13, 53-57. https://doi.org/10.1590/1677-3225v13n1a11

[40] de Santi, M.E.S.O., Prates, R.A., França, C.M., Lopes, R.G., Sousa, A.S., Ferreira, L.R., Bussadori, S.K., Fernandes, A.U. and Deana, A.M. (2018) Antimicrobial Photodynamic Therapy as a New Approach for the Treatment of Vulvovaginal Candidiasis: Preliminary Results. Lasers in Medical Science, 33, 1925-1931.

https://doi.org/10.1007/s10103-018-2557-y

[41] da Luz, F.B. (2014) Aplicação de Terapia Fotodinâmica (PDT) Usando Luz LED Azul Sobre Culturas de Candida albicans-in Vitro. Universidade Federal de Pelotas, Pelotas.

[42] Calzavara-Pinton, P., Rossi, M.T., Sala, R. and Venturini, M. (2012) Photodynamic Antifungal Chemotherapy. Photochemistry and Photobiology, 88, 512-522. https://doi.org/10.1111/j.1751-1097.2012.01107.x

[43] Traboulsi, R.S., Mukherjee, P.K., Chandra, J., Salata, R.A., Jurevic, R. and Ghannoum, M.A. (2011) Gentian Violet Exhibits Activity against Biofilms Formed by Oral Candida Isolates Obtained from HIV-Infected Patients. Antimicrobial Agents and Chemotherapy, 55, 3043-3045. https://doi.org/10.1128/AAC.01601-10

[44] Gomes-De-Elvas, A.R., Palmeira-De-Oliveira, A., Gaspar, C., Gouveia, P., Palmeira-De-Oliveira, R., Pina-Vaz, C., Rodrigues, A.G. and Martinez-De-Oliveira, J. (2012) In Vitro Assessment of Gentian Violet Anti-Candida Activity. Gynecologic and Obstetric Investigation, 74, 120-124. https://doi.org/10.1159/000338899

[45] Freitas, D.D. (2015) Avaliação In Vitro Da Curcumina Frente Às Cepas de Candida spp. e Cryptococcus neoformans Resistentes Ao Fluconazol. Universidade Federal do Ceará, Fortaleza.

http://repositorio.ufc.br/bitstream/riufc/13765/1/2015 dis ddfreitas.pdf

[46] Dovigo, L.N., Pavarina, A.C., Ribeiro, A.P.D., Brunetti, I.L., Costa, C.A.D.S., Jacomassi, D.P., Bagnato, V.S. and Kurachi, C. (2011) Investigation of the Photodynamic Effects of Curcumin against Candida albicans. Photochemistry and Photobiology, 87, 895-903. https://doi.org/10.1111/j.1751-1097.2011.00937.x

[47] Jurevic, R.J., Traboulsi, R.S., Mukherjee, P.K., Salata, R.A. and Ghannoum, M.A. (2011) Identification of Gentian Violet Concentration That Does Not Stain Oral Mucosa, Possesses Anti-Candidal Activity and Is Well Tolerated. European Journal of Clinical Microbiology and Infectious Diseases, 30, 629-633.

https://doi.org/10.1007/s10096-010-1131-8

[48] Mulu, A., Kassu, A., Anagaw, B., Moges, B., Gelaw, A., Alemayehu, M., Belyhun, Y., Biadglegne, F., Hurissa, Z., Moges, F. and Isogai, E. (2013) Frequent Detection of 
“Azole" Resistant Candida Species among Late Presenting AIDS Patients in Northwest Ethiopia. BMC Infectious Diseases, 13, Article No. 82.

https://doi.org/10.1186/1471-2334-13-82

[49] Traboulsi, R.S., Mukherjee, P.K. and Ghannoum, M.A. (2008) In Vitro Activity of Inexpensive Topical Alternatives against Candida spp. Isolated from the Oral Cavity of HIV-Infected Patients. International Journal of Antimicrobial Agents, 31, 272-276. https://doi.org/10.1016/j.ijantimicag.2007.11.008

[50] Kondo, S., Tabe, Y., Yamada, T., Misawa, S., Oguri, T., Ohsaka, A. and Miida, T. (2012) Comparison of Antifungal Activities of Gentian Violet and Povidone-Iodine against Clinical Isolates of Candida Species and Other Yeasts: A Framework to Establish Topical Disinfectant Activities. Mycopathologia, 173, 21-25.

https://doi.org/10.1007/s11046-011-9458-y 